\title{
Ne baissons pas les bras !
}

Dernière mise à jour : 18 janvier 2017

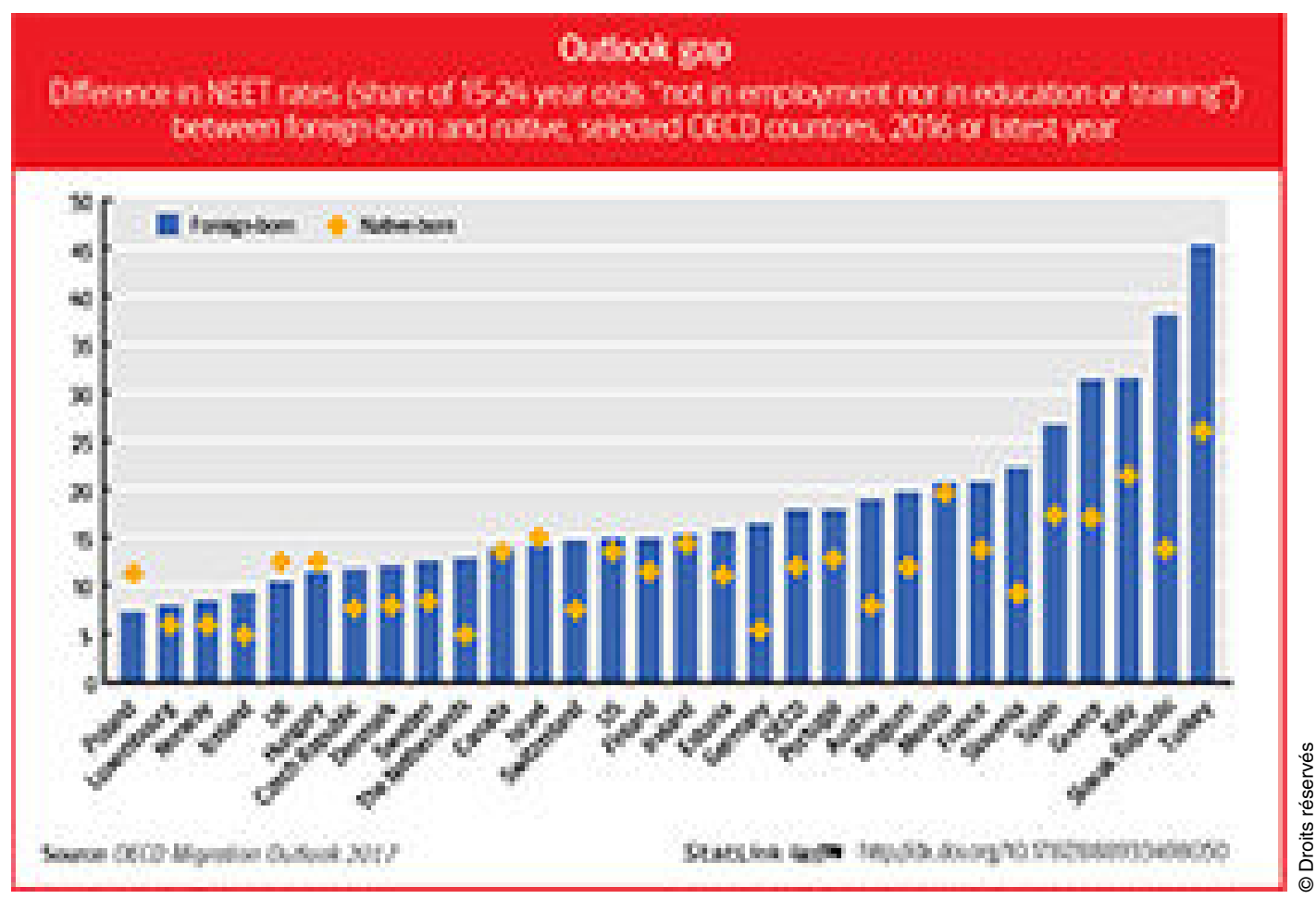

Ne baissons pas les bras!

La profonde récession de 2007-2008 a durement frappé les jeunes, et plus brutalement encore les jeunes nés à l'étranger. Dans les pays de l'OCDE, 13,9\% des autochtones de 15 à 29 ans n'étaient ni en emploi, ni en études, ni en formation (Not in Education, Employment or Training ou NEET) en 2015, contre 21,5 $\%$ des allochtones de la même classe d'âge.

Pour autant, la catégorie des jeunes nés à l'étranger regroupe des populations très différentes : certains sont arrivés récemment, tandis que d'autres sont arrivés avec leurs parents lorsqu'ils étaient enfants, et ont suivi toute leur scolarité dans le pays d'accueil. Néanmoins, lorsque l'on compare la proportion de jeunes NEET dans les populations autochtone et allochtone, les difficultés liées à la langue constituent souvent, sinon toujours, un obstacle pour les jeunes nés à l'étranger. Par ailleurs, même si les jeunes immigrés arrivés récemment dans le pays d'accueil sont qualifiés, leurs diplômes peuvent être mal connus des employeurs potentiels. 
Aujourd'hui, dix ans après la crise, les jeunes nés à l'étranger se trouvent non seulement sans emploi, mais aussi de plus en plus difficilement embauchables. Dans la plupart des pays de l'OCDE, la proportion moyenne de jeunes NEET allochtones a augmenté de six points de pourcentage par rapport aux autochtones, pour s'établir à $30 \%$. Il n'est pas étonnant, dans ce contexte, qu'une grande partie des jeunes nés à l'étranger baissent les bras. Aux États-Unis, la part des jeunes de 15 à 24 ans nés à l'étranger qui continuent de rechercher un emploi a reculé de plus de 2 points de pourcentage. En Australie, cette baisse est de 3,7 points. Les responsables politiques doivent redoubler d'efforts pour leur offrir de meilleures perspectives, afin que les travailleurs nés à l'étranger puissent aussi contribuer davantage à l'économie, et espérer une meilleure rémunération, un emploi de qualité et une meilleure santé.

CL'Observateur de l'OCDE n³12 T4 2017 